\title{
Ceritinib Enhances the Efficacy of Substrate Chemotherapeutic Agent in Human ABCB1-Overexpressing Leukemia Cells In Vitro, In Vivo and Ex-Vivo
}

\author{
Li Yang ${ }^{a, b}$ Manjun Li ${ }^{a, b} \quad$ Fang Wang ${ }^{b}$ Chen Zhen ${ }^{b}$ Min Luo ${ }^{b}$ Xiaona Fang ${ }^{b}$ \\ Hong Zhang ${ }^{b}$ Jianye Zhang ${ }^{c}$ Qingshan Li ${ }^{a}$ Liwu Fu ${ }^{b}$ \\ aDepartment of Hematology, Guangzhou First People's Hospital, Guangzhou Medical University, \\ Guangzhou, bGuangdong Esophageal Cancer Institute, State Key Laboratory of Oncology in South \\ China, Sun Yat-Sen University Cancer Center, Guangzhou, 'College of Pharmacy, Guangzhou Medical \\ University, Guangzhou, China
}

\section{Key Words}

Ceritinib • ATP-binding cassette $(A B C) \cdot$ Leukemia $・ A B C B 1 \cdot$ Multidrug resistance (MDR)

\begin{abstract}
Background/Aims: Multidrug resistance (MDR) triggered by ATP binding cassette (ABC) transporters, such as $A B C B 1, A B C C 1$, and $A B C G 2$, is a key obstacle for successful cancer chemotherapy. There is currently no FDA-approved MDR modulator that can be used in clinic. Ceritinib, a selective ALK inhibitor, has been approved as the second-line treatment for ALKpositive non-small cell lung cancer. Here, we examined the role of ceritinib in leukemia associated MDR in therapy. Methods: The cell proliferation was detected by MTT assay. The flow cytometry was used to detect the expression of cell surface protein and to detect the accumulation and efflux of rhodamine 123 (Rh123) or doxorubicin (Dox) in cells. The RT-PCR and Western blot were performed to detect the gene expression and protein expression levels, respectively. Results: We found that ceritinib enhanced the efficacy of substrate chemotherapeutic agent in ABCB1-overexpressing K562/adr leukemia cells both in vitro and in vivo models, but neither in sensitive parental K562 leukemia cells nor in ABCC1-overexpressing HL-60/adr leukemia cells. Mechanistically, ceritinib significantly increased the intracellular accumulation of Rh123 or Dox but did neither alter ABCB1 expressions at both protein and mRNA levels nor block the phosphorylations of AKT and ERK1/2 at the concentration of MDR reversal. Importantly, ceritinib also increased the intracellular accumulation of Dox and enhanced the efficacy of Dox in primary leukemia cells in ex-vivo. Conclusion: Our results suggested that ceritinib enhanced the efficacy of substrate chemotherapeutic agent on inhibition of leukemia cell growth in vitro, in vivo and ex-vivo, which linked to block $A B C B 1$ function, pumping out its substrate conventional chemotherapeutic agent, thereby increasing the intracellular accumulation. These suggest the combination of ceritinib and substrate chemotherapeutic drugs maybe an effective treatment of resistant leukemia patients with ABCB1-mediated MDR.

(C) 2018 The Author(s)

Published by S. Karger AG, Basel

Prof. Liwu Fu

Cancer Center, Sun Yat-Sen University, Guangzhou 510060 (China); Department of

and Prof. Qingshan Li

Hematology, Guangzhou First People's Hospital, Guangzhou Medical University,

Guangzhou 510180 (China); E-Mail Fulw@mail.sysu.edu.cn, drliqingshang@126.com
\end{abstract}




\section{Introduction}

In the hematological neoplasm, leukemia originates from abnormal hematopoietic stem cells which can result in a high number of abnormal white blood cells. Allogeneic hematopoietic stem cell transplantation (HSCT) is a radical therapy for leukemia, while it is only suitable for a minority of leukemia patients because of the lack of enough bone marrow donors. Therefore, most leukemia patients must be treated with conventional or targeted chemotherapy. Conventional chemotherapy, using cytotoxic drugs to inhibit the proliferation of malignant cells or destroy malignant cells, has become the most common and primary clinical strategy in the treatment of blood malignancies. The targeted chemotherapeutic drugs, such as the first FDA-approved tyrosine kinase inhibitor (TKI) imatinib has been used for treating chronic myeloid leukemia (CML) patients with oncoprotein BCR-ABL expression, which has resulted in well-pleasing and remarkable treatment outcomes for the majority of CML patients [1-3]. Unfortunately, multidrug resistance (MDR) is still the main reason for the failure and relapse of leukemia chemotherapy using conventional or targeted chemotherapeutic drugs.

MDR is a multi-mechanism phenomenon. The overexpression of $A B C$ transporter proteins such as ABCB1, ABCC1 and ABCG2 has been proved to play a vital role in the development of MDR in cancer cells [4,5]. The human genome contains $49 \mathrm{ABC}$ genes, which are divided into $A$ to $G$ seven subfamilies. The $A B C$ proteins encoded by these genes decrease intracellular drug accumulation by transporting cytotoxic anti-cancer drug outside of cancer cells. Hence, overexpression of $\mathrm{ABC}$ transporter can increase drug efflux and decrease the intracellular drug concentration, thereby preventing the tumor cells from being inhibited or killed. These survived tumor cells finally acquire drug resistance [6]. Among the ABCprotein family, proteins encoded by the ABCB1 (MDR1), ABCC1 (MRP1), and ABCG2 (MXR and BCRP) genes are the best known to associate with MDR [7]. Particularly, ABCB1 protein is the most frequently observed and widely studied molecular cause of MDR in ABC-protein family [8-10]. Normally, ABCB1 is often distributed in the kidney, pancreas, liver and gut, as a protection mechanism in the human body. Its overexpression has been reported to be related to poor response to chemotherapy and poor overall survival in leukemia patients $[11,12]$. Based on this situation, various kinds of drugs including lapatinib [13], cediranib [14], alectinib [15], and gefitinib [16] have been reported to reverse MDR by inhibiting the function of ABCB1. Although MDR modulators have been extensively studied, no MDR modulator has ever been approved by FDA for clinic application.

On the other hand, targeted chemotherapeutic drugs, such as tyrosine kinase inhibitors (TKIs), have been administrated to fight against cancer for decades. TKI is generally used as a monotherapy in clinic. However, drug combinations acting synergistically to kill cancer cells have increasingly become an important approach in cancer chemotherapy to prevent or delay the drug resistance. TKIs such as gefitinib [16], erlotinib [17], lapatinib [18], apatinib [19], crizotinib [20], nilotinib [21] can enhance the efficacy of substrate anticancer agent in MDR cells. Ceritinib (LDK378, Novartis Pharmaceuticals) is an ATP-competitive, potent and selective second-generation ALK inhibitor which was approved by FDA on April 29, 2014 to treat non-small cell lung cancer $[22,23]$. Since ceritinib mechanistically acts like other TKIs, it is conceivable that ceritinib may also sensitize the ABC transporter overexpressing leukemia cells to substrate chemotherapeutic drug, thereby reversing MDR.

\section{Materials and Methods}

\section{Chemicals and reagents}

Ceritinib (LDK378) was purchased from Selleck Chemical (Houston, TX, USA). The molecular structure of ceritinib is shown in Fig. 1A. Monoclonal antibody against ABCB1, extracellular signal-regulated protein kinases 1 and 2 (ERK1/2), p-ERK, AKT and p-AKT were purchased from Santa Cruz Biotechnology (Santa Cruz, CA, USA). The antibody against glyceraldehyde-3-Phosphate dehydrogenase (GAPDH) was purchased 
Yang et al.: Ceritinib Reverses Drug Resistance in Leukemia

Fig. 1. The molecular structure of ceritinib and the cytotoxicity of ceritinib. (A) The molecular structure of ceritinib. (B) MTT cytotoxicity assay was assessed in ABCB1 over - expressing K562/adr cells and their parental sensitive K562

A

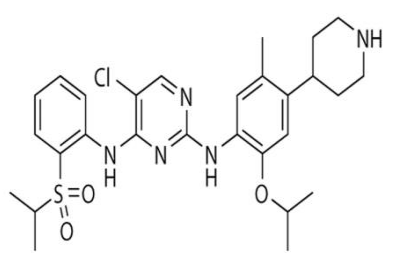

B

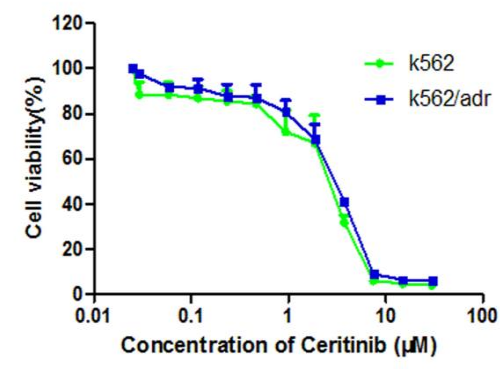

cells. Independent

experiments were performed at least three times and results from a representative experiment were shown.

from Kangcheng (Shanghai, China). RPMI-1640 and fetal bovine serum (FBS) were obtained from Gibco BRL (Thermo Fisher Scientific Inc., Waltham, MA, USA). Lymphocyte separation medium was from Zhanchen Inc. (Shanghai, China). Doxorubicin (Dox), paclitaxel, cisplatin, verapamil (VRP), dimethyl sulfoxide (DMSO), rhodamine123, and 3-(4, 5-dimethylthiazol-2yl)-2, 5-diphenyl tetrazolium bromide (MTT), were all purchased from Sigma-Aldrich (St. Louis, MO, USA).

\section{Cell lines and patient samples}

It has been reported that the ABCB1 is expressed in AML/CML patients [24]. We obtained the bone marrow samples from AML/CML patients according to the FAB classification after getting their informed consent, and this study was approved by the Ethics Review Committee at Sun Yat-Sen University Cancer Center. The mononuclear cells were separated by lymphocyte separation medium and cultured in RPMI 1640 medium supplemented with $10 \% \mathrm{FBS}$ at $37^{\circ} \mathrm{C}$ in a humidified atmosphere of 5\% C02. K562, K562/ adr (K562/adr cells stably overexpress ABCB1 because of the long-term exposure of the parental K562 cell line to the ABCB1 substrate Dox), HL60, and Dox-selected ABCC1 overexpressing derivative cell line HL60/ adr were also cultured in the same medium mentioned above.

\section{Cell cytotoxicity assay}

The MTT assay was used to assess cytotoxicity as described previously [25]. Briefly, the cells (about 4000-8000 cells) growing in logarithmic phase were incubated overnight in 96-well microplates to the desired confluency before they were treated with the indicated concentration of each conventional chemotherapeutic drugs together with or without a fixed concentration of ceritinib or verapamil. When the cells were incubated in a humidified atmosphere containing $5 \% \mathrm{CO}_{2}$ at $37^{\circ} \mathrm{C}$ for $68 \mathrm{~h}$, MTT $(5 \mathrm{mg} / \mathrm{ml}, 20$ $\mu \mathrm{L}$ ) was added into each well, and $4 \mathrm{~h}$ later, the medium was discarded gently after centrifugation and 100 $\mu \mathrm{L}$ DMSO was added into each well to dissolve the formazan product from the metabolism of MTT. Finally, optical density was measured at $540 \mathrm{~nm}$, with background subtraction at $670 \mathrm{~nm}$ by a Model 550 Microplate Reader (Bio-Rad, Hercules, CA, USA). The half maximal (50\%) inhibitory concentration (IC ${ }_{50}$ ) value of a substrate was calculated by the Bliss method and the $\mathrm{IC}_{50}$ results were presented as mean \pm standard deviation (SD) [26]. The fold reversal of MDR was calculated as previously described [27]. All experiments were repeated at least three times.

\section{In vivo experiment}

We purchased athymic nude mice (5-6 weeks old) from the Vital River (Beijing, China). About $1 \times 10^{7}$ K562/adr cells were harvested and implanted subcutaneously under the shoulder in a nude mouse to establish the K562/adr cells xenograft model [27]. When the tumors reached a mean diameter of $0.5 \mathrm{~cm}$, the mice were randomized into four groups and treated as follows: (1) saline (p.o., q2d× 12); (2) ceritinib (25 mg/kg, p.o., q2d× 12); (3) Dox (2 mg/kg, i.p., q2d× 12); (4) ceritinib (25 mg/kg, p.o., q2d× 12 given $1 \mathrm{~h}$ before injecting Dox + Dox ( $2 \mathrm{mg} / \mathrm{kg}$, i.p., q2d×12). The body weights of the animals and the two perpendicular diameters (A and B) of each tumor were recorded every 2 days, and tumor volume (V) was estimated 
according to the following formula: $V=(\pi / 6)[(A+B) / 2]^{3}$. The curve of tumor growth was drawn according to tumor volume and duration of implantation. The mice were anesthetized and sacrificed at the end of the observation period. Tumor tissues were excised from the mice and their weights were recorded. The ratio of growth inhibition (IR) was calculated according to the following formula:

$$
\mathbb{R}(\%)=1-\frac{\text { tumor weight of experimental group }}{\text { tumor weight of control group }} \times 100 \%
$$

The accumulation of Dox and rhodamine 123 (Rho 123) in leukemia cells

Flow cytometry assay was performed to measure the effect of ceritinib on the intracellular accumulation of Dox and Rho123 in leukemia cells as previously described [28]. Briefly, the cells were cultured in the 6-well microplates and grown overnight. Then the cells were treated with saline or one of the different concentrations of ceritinib $(0.5 \mu \mathrm{M}, 0.25 \mu \mathrm{M}, 0.125 \mu \mathrm{M})$ or $10 \mu \mathrm{M}$ verapamil (VRP) (VRP was used as a positive control inhibitor in ABCB1-overexpressing cells.) at $37^{\circ} \mathrm{C}$ for $3 \mathrm{~h}$. Following the saline or ceritinib or VRP treatment, then $10 \mu \mathrm{M}$ Dox was added to each well and cells were further incubated for $3 \mathrm{~h}$ or $5 \mu \mathrm{M}$ Rho 123 was added to each well and cells were further incubated for $0.5 \mathrm{~h}$, respectively. The cells were then harvested, washed 3 times with ice-cold PBS, and analyzed by CytomicsFC500 flow cytometer (Beckman Coulter, USA). All experiments were repeated at least three times.

\section{Dox efflux examined in leukemia cells}

Dox efflux was performed following a modification of the methods described earlier [29]. In brief, K562 and $\mathrm{K} 562 / \mathrm{adr}$ cells were treated with $10 \mu \mathrm{M}$ Dox for $3 \mathrm{~h}$ at $37^{\circ} \mathrm{C}$, then the cells were washed three times with ice-cold PBS buffer and subsequently maintained at $37^{\circ} \mathrm{C}$ with RPMI 1640 medium supplemented with $10 \%$ FBS without Dox in the presence or absence of $0.5 \mu \mathrm{M}$ ceritinib for $0,15,30,60,90$ and $120 \mathrm{~min}$, until cells were collected and washed three times with ice-cold PBS buffer. Finally, cells were resuspended in icecold PBS buffer for immediate flow cytometric analysis (Beckman Coulter; CytomicsFC500). All experiments were repeated at least three times.

\section{Western blot analysis}

The Western blot was performed as previously described [30]. The protein expression of ABCB1 or the phosphorylation of AKT and ERK1/2 were evaluated in the ABCB1-overexpressing k562/adr cells and in their parental k562 cells after treatment with ceritinib $(0.125,0.25$, and $0.5 \mu \mathrm{M})$ for $48 \mathrm{~h}$. After treatment under the above conditions, cells were harvested and washed twice with ice-cold PBS buffer. Next, total cell lysates were generated in cell lysis buffer (1×PBS, 0.1\% SDS, 1\% Nonidet P-40, 0.5\% sodium deoxycholate, $100 \mathrm{mg} / \mathrm{mL}$ phenylmethylsulfonyl fluoride, $10 \mathrm{mg} / \mathrm{mL}$ leupeptin, $10 \mathrm{mg} / \mathrm{mL}$ aprotinin). An equal amount of total protein from each cell lysate was resolved on sodium dodecyl sulfate-polyacrylamide gel electrophoresis (SDS-PAGE) gel and then transferred to PVDF membrane (Pall, USA). After blocking with 5\% nonfat milk for one hour, PVDF membranes were sequentially incubated with the primary antibodies overnight at $4{ }^{\circ} \mathrm{C}$ and secondary antibodies for two hours at room temperature. After washing three times for 30 minutes with TBST buffer, the signal was developed using the enhanced chemiluminescence kit (\#1705061, Bio-Rad, CA, USA) and detected by a Kodak medical X-ray processor (Kodak, Rochester, NY, USA).

\section{PCR and real-time quantitative PCR}

ABCB1 mRNA expression levels were assayed as previously described [30]. The PCR primers were 5'-CCCATCATTGCAATAGCAGG-3' (forward) and 5'-GTTCAAACTTCTGCTCCTGA-3' (reverse) for ABCB1, and $5^{\prime}$-CTTTGGTATCGTGGAAGGA-3' (forward) and 5'-CACCCTGTTGCTGTAGCC-3' (reverse) for GAPDH. After 35 cycles of amplification, products were separated by 1.0\% agarose gel electrophoresis. Real-time quantitative PCR was performed using SYBR GREEN Mix (Molecular Research Center, Cincinnati, OH, USA). Relative quantification of ABCB1 was analyzed using the $2^{-\Delta \Delta C t}$ method after normalization with GAPDH expression in each sample.

\section{Detection of cell surface expression of ABCB1 by flow cytometer}

K562/adr and the leukemic blasts (We transferred each bone marrow or blood sample to a green topped tube containing heparin, then the mononuclear cells were isolated by Ficoll-Hypaque density centrifugation.) were collected and washed three times with an isotonic ice-cold PBS buffer supplemented 
Yang et al.: Ceritinib Reverses Drug Resistance in Leukemia

with $0.5 \%$ bovine serum albumin (BSA). For ABCB1 expression analysis, approximately $1 \times 10^{6}$ cells $(100$ $\mu \mathrm{L}$ ) were incubated at $4{ }^{\circ} \mathrm{C}$ for $45 \mathrm{~min}$ in the dark with $10 \mu \mathrm{L}$ of PE-conjugated anti-human P-gp (Beckman Coulter, Fullerton, CA, USA), then the cells were washed twice with PBS buffer supplemented with $0.5 \%$ BSA and resuspended in $400 \mu \mathrm{L}$ PBS buffer for flow cytometric analysis. Isotype control samples were treated with PE-conjugated mouse IgG2a antibody. All experiments were repeated at least three times.

\section{Availability of Data and Materials}

The authenticity of this article has been validated by uploading the key data onto the Research Data Deposit public platform (www.researchdata.org.cn),which the approval RDD number as RDDB2018000280

Statistical analysis

The data were expressed as mean \pm SD. All experiments were repeated at least three times, and the statistical analyses were determined by Student's t-test. Statistical significance was considered when *P $<0.05$ or ${ }^{* *} \mathrm{P}<0.01$.

\section{Results}

Ceritinib potentiated the cytotoxicity of the conventional chemotherapeutic drugs in ABCB1-overexpressing leukemia cells in vitro

The chemical structural formula of ceritinib was presented in figure 1A. To investigate whether ceritinib could reverse MDR in vitro, we examined the cytotoxicity of ceritinib by MTT assay. The $\mathrm{IC}_{50}$ values were $1.91 \pm 0.4 \mu \mathrm{M}$ and $1.15 \pm 0.04 \mu \mathrm{M}$ for K562/adr cells and K562 cells, respectively. More than 85\% of both K562/adr cells and K562 cells survived at the concentration of $0.5 \mu \mathrm{M}$ ceritinib (Fig. 1B). Therefore, $0.5 \mu \mathrm{M}$ of ceritinib was chosen as a maximum concentration used for combination treatment with ABCB1 substrate anti-cancer drug. The $\mathrm{IC}_{50}$ values of the anti-cancer drugs in sensitive and resistant cells in the absence or presence of ceritinib were shown in Table 1. Ceritinib was showed a concentrationdependent decrease in the $\mathrm{IC}_{50}$ values of Dox and paclitaxel (both are ABCB1 substrates) in $\mathrm{K} 562 / \mathrm{adr}$ cells, but ceritinib did not alter the cytotoxicity of cisplatin which is not an ABCB1 substrate. But only a slight enhancements of substrate agent Dox and paclitaxel and non-substrate agent cisplatin were observed in their parental sensitive K562 cells in the presence of ceritinib, even at the maximum reversal concentration of $0.5 \mu \mathrm{M}$. In addition, ceritinib showed no significant reversal MDR effect on ABCC1-overexpressing HL60/adr cells. These results suggest that ceritinib enhances the sensitivity of ABCB1-overexpressing MDR leukemia cells to the conventional substrate chemotherapeutic drugs, but ceritinib has negligible effects on their parental sensitive cells.

Ceritinib enhanced the efficacy of Dox in ABCB1-overexpressing MDR leukemia cell xenograft model in vivo

An ABCB1-overexpressing MDR K562/adr cell xenograft model was established in nude mice to evaluate whether ceritinib could reverse the resistance to Dox in vivo. there was no significant difference in tumor size among animals treated with saline, ceritinib or Dox group. However, there was a significant inhibition of tumor growth in the group treated with a combination of ceritinib and Dox, compared with other single drug groups or saline control group ( $\mathrm{P}<0.05$; Fig. $2 \mathrm{~A}$ and Fig. $2 \mathrm{~B})$. The mean weights of tumors excised from mice were $2.32 \pm 0.26,2.21 \pm 0.31,2.21 \pm 0.57$, and $0.88 \pm 0.32(\mathrm{~g})$ for saline, Dox, ceritinib, and combination group, respectively. Furthermore, we did not observe the death of mice or apparent body weight loss in the combination treatment group at the treated doses (Fig. 2C), suggesting that the combination regimen did not increase toxicity.

Ceritinib enhanced the accumulation of Dox and Rho123 in ABCB1-overexpressing MDR leukemia cells

The results described above revealed that ceritinib could enhance the sensitivity of ABCB1-overexpressing MDR leukemia cells to the conventional chemotherapeutic drugs 
that were ABCB1 substrates in vitro and in vivo. To investigate the potential mechanisms for the MDR reversal by ceritinib, we examined the i n tra c e l l u l a r accumulation of Dox and Rho 123 in the presence or absence of ceritinib in ABCB1overexpressing MDR leukemia cells and their parental sensitive cells. Our results showed that the intracellular accumulations of Dox and Rho123 in K562/adr cells were significantly lower than that in their parental sensitive cells. Importantly, ceritinib was found to significantly increase the intracellular accumulations of Dox (fluorescent substrate drug of ABCB1) and Rho123 (fluorescent probe substrate of ABCB1) in a concentrationdependent manner in K562/adr cells, while no notable change was observed in their parental cells (Fig. 3). These results suggest that ceritinib increases the intracellular accumulation of chemotherapeutic drugs in ABCB1-overexpressing MDR leukemia cells.

\section{Ceritinib inhibited the efflux of Dox in ABCB1- overexpressing $\quad M D R$ leukemia cells}

Since ceritinib increased the intracellular accumulation of Dox and Rho123 in ABCB1overexpression MDR cells, we next examined whether the increased accumulation of anticancer drugs was due to the inhibition of efflux of anti-cancer drugs. The efflux of Dox over $2 \mathrm{~h}$ after an initial drug accumulation

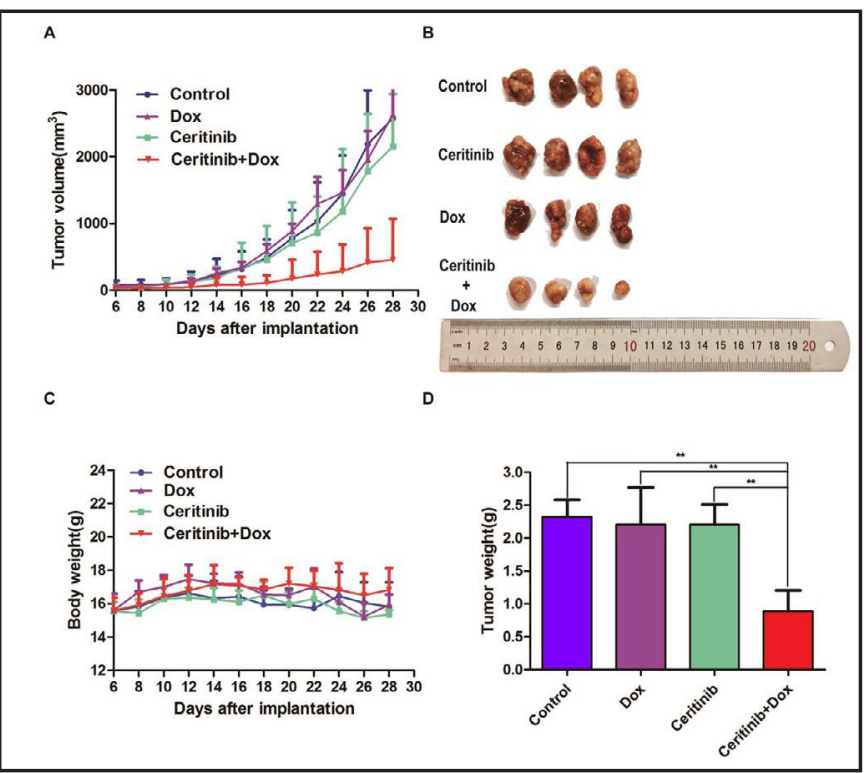

Fig. 2. Ceritinib enhanced the anti-leukemia effect of Dox in the K562/adr cell xenograft model in nude mice. (A) The tumor growth curve was drawn according to the tumor volume and duration of K562/adr cell implantation. Data of tumor volume was shown as mean \pm SD for each group $(n=4)$. (B) The image of tumor size in four groups excised from the mice on the 28th day after implantation. (C) Changes in body weight. Each point represents the mean \pm SD of body weight from four mice in the group. The four treatment groups are: (1) saline (p.o., q2d × 12); (2) Dox (20 mg/kg, i.p., q2d × 12); (3) Ceritinib (25 mg/kg, p.o., q2d × 12); and (4) Ceritinib (25 mg/kg, p.o., q2d × 12) + Dox (20 mg/kg, i.p., $\mathrm{q} 2 \mathrm{~d} \times 12), 1 \mathrm{~h}$ later. (D) Mean tumor weight $(\mathrm{n}=4)$ was examined after being excised from the mice on the 28th day after implantation. Results are represented as the mean \pm SD. ${ }^{*} \mathrm{P}<0.05$ and ${ }^{* *} \mathrm{P}<$ 0.01 denote the significant differences from the control group. 
Fig. 3. Effect of ceritinib on the intracellular accumulation of Dox and Rho 123 in K562/ adr and K562 cells. The accumulation of Dox (A1, B1) and Rho 123 (A2, B2) in K562/adr and $\mathrm{K} 562$ were measured by flow cytometric analysis, respectively. The results are presented as fold-change in fluorescence intensity relative to control MDR cells. They were calculated by dividing the fluorescence intensity of each sample with that of MDR cells treated with Dox or Rho123 alone. Results are represented as the mean $\pm \mathrm{SD} .{ }^{*} \mathrm{P}<0.05$ and ${ }^{* *} \mathrm{P}<$ 0.01 denote the significant differences from the control group.

was monitored and the results were showed in Fig. 4. As expected, due to the ABCB1 overexpression in K562/ adr cells, Dox retention dropped remarkably from $100 \%$ ( $0 \mathrm{~h}$ efflux) to about $39.11 \%$ ( $2 \mathrm{~h}$ efflux), while ceritinib $(0.5 \mu \mathrm{M})$ was found to significantly increase Dox retention in K562/adr cells to $63.02 \%(\mathrm{p}<0.05)$ of the level attained at the $2 \mathrm{~h}$ time

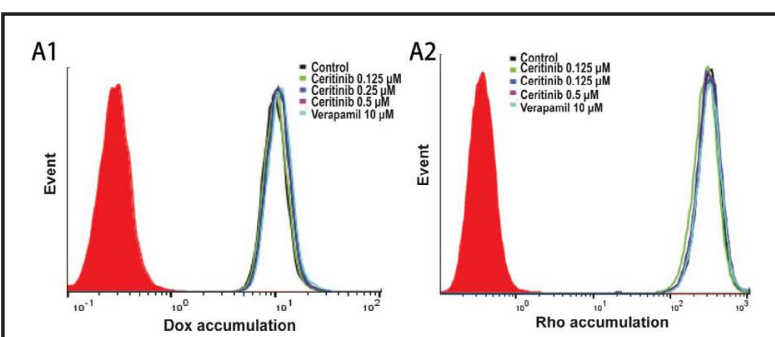

$\begin{array}{ll}\text { B1 } & \text { B2 }\end{array}$

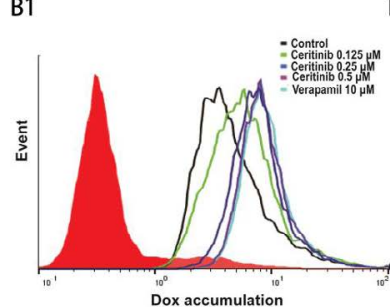

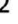
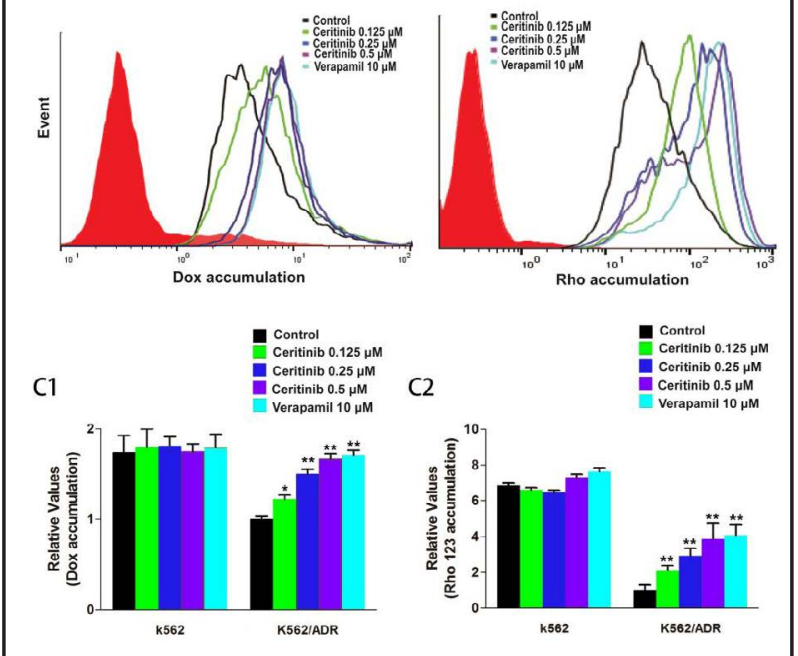

point. Interestingly, we did not find any significant difference in sensitive parental K562 cells with or without ceritinib $(0.5 \mu \mathrm{M})$. These results showed that ceritinib inhibited drug efflux function of ABCB1 in K562/adr cells, but ceritinib did not influence drug efflux in their parental sensitive K562 cells.

Ceritinib did not alter the expression level of $A B C B 1$ in K562/adr cells

ABC transporter-mediated MDR may be circumvented by downregulating the expression of the transporters or inhibiting their transport function. Therefore, we determined the effect of ceritinib on the mRNA and protein expression levels of ABCB1 using RT-PCR and Western

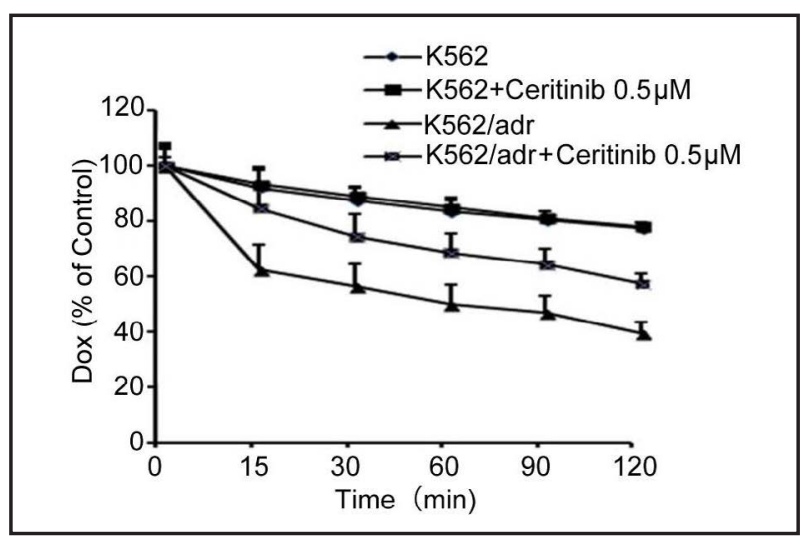

Fig. 4. Effect of ceritinib on the efflux of Dox in K562 and K562/adr cells treated with or without $0.5 \mu \mathrm{M}$ ceritinib. Time course of Dox efflux was measured in K562/adr and K562 cells treated with or without $0.5 \mu \mathrm{M}$ ceritinib. The dot means triplicate determinations, bar means standard deviation (SD). blot analysis, respectively. Our results, which were observed in K562/adr cells treated with $0.125,0.25$, or $0.5 \mu \mathrm{M}$ ceritinib for $48 \mathrm{~h}$ or $0.5 \mu \mathrm{M}$ ceritinib in different time of $72 \mathrm{~h}$, showed no significant difference in ABCB1 expression at the mRNA or protein level (Fig. 5). Therefore, it is likely that ceritinib reverses MDR by inhibiting the transport function of ABCB1 rather than downregulating the expression of ABCB1 transporter. 
Fig. 5. Effect of ceritinib on the expression of ABCB1 in K562/adr and K562. The protein level of ABCB1 was measured by Western blot, and mRNA level was measured by RT-PCR and Q-PCR (quantitative real-time PCR) . (A, B) Ceritinib did not alter the protein or mRNA level in K562/adr cells. (C) Q-PCR was further applied to confirm constant mRNA level in K562/adr cells. (D) The cell surface expression of ABCB1 was measured by Flow $\mathrm{Cy}$ tometer. The expression of ABCB1 did not change in the presence or absence of ceritinib in K562/ adr cells. All these experiments were repeated at least three times, and a representative experiment is shown in each panel.

Ceritinib had no effect on the blockage of AKT and ERK1/2 phosphorylation in K562/adr cells at its MDR reversing concentrations

Previous studies have shown that activation of the AKT and ERK1/2 pathways resulted in the resistance to anti-cancer drugs in tumor cells [31,32]. To determine whether the reversal MDR by ceritinib linked to the blockage of phosphorylation status of AKT and ERK1/2 in K562/adr cells and their parental cells, we examined the total and phosphorylation levels of AKT and ERK1/2 after concentration and time-dependently treating the cells with ceritinib. As shown in Fig. 6, there was no significant alteration in the total and phosphorylated levels of AKT or ERK1/2 in the presence of ceritinib at the concentration of reversal MDR. These results suggest that the enhancement effect of ceritinib on ABCB1overexpressing cells is independent of the inhibition of the total and phosphorylated AKT and ERK1/2 levels.

\section{Ceritinib reversed MDR in ex vivo}

To explore whether ceritinib could reverse ABCB1-mediated MDR in ex vivo, bone marrow samples were collected from drug-resistant leukemia patients [33]. We examined 10 leukemia patient's bone marrow samples in total. Among them, one patient was detected having a significantly higher ABCB1 expression (the ratio of ABCB1 expression is $44.1 \%$ ) than the other patients (the ratio of ABCB1 expression is below 1\%). We then examined the effect of ceritinib on the
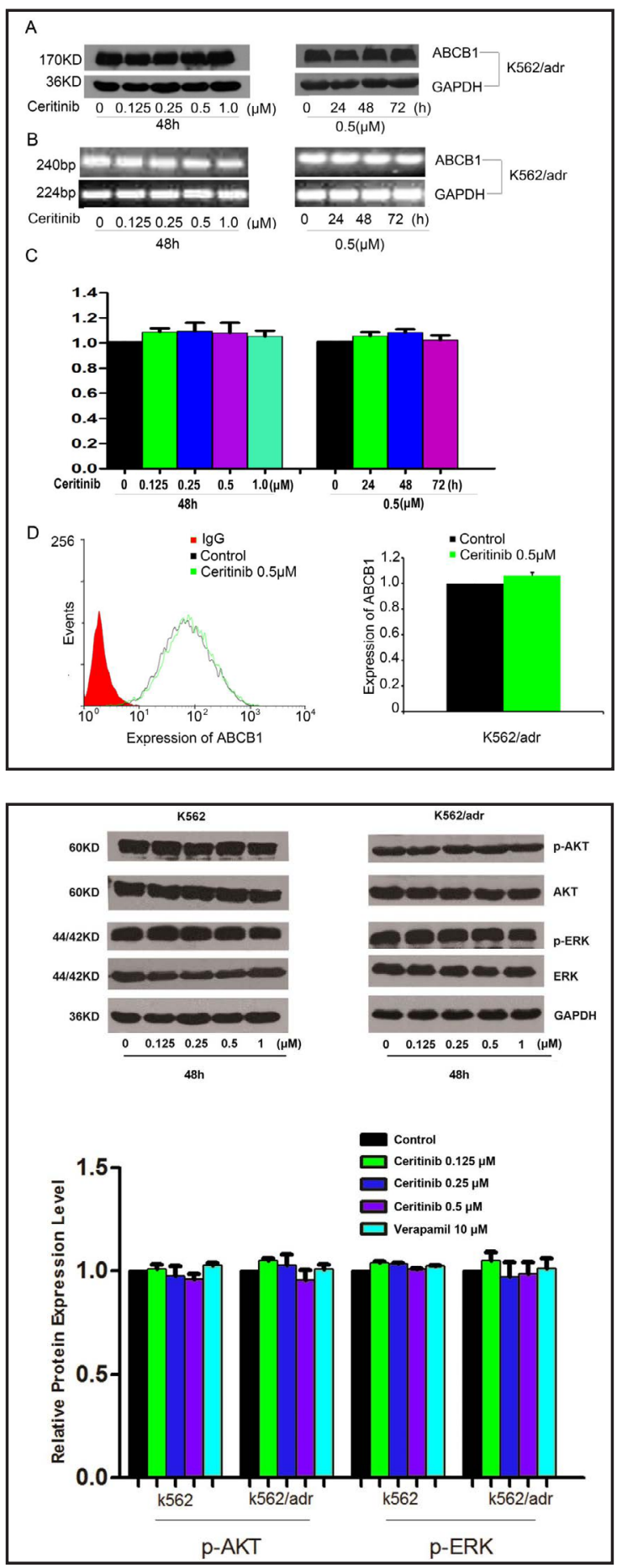

Fig. 6. Effect of ceritinib on the phosphorylation of AKT and ERK1/2. K562 and K562/adr cells were treated with ceritinib at various concentrations for $48 \mathrm{~h}$. An equal amount of total protein for each sample was loaded for Western blot analysis. Independent experiments were performed at least three times and results from a representative experiment were shown. 
intracellular accumulation of Dox in leukemic blast cells from two patients (one was more than $44 \%$ ABCB1 expression; the other was less than 1\% ABCB1 expression as negative control) using flow cytometric analysis. Our results showed that ceritinib increased the intracellular accumulation of Dox in leukemic blast cells with ABCB1-overexpressing patient (Fig. 7B1, C1), but not in leukemic blast cells with negative ABCB1 expressing patient (Fig. 7B2, C2). In addition, we used the MTT assay to assess the sensitizing effect of ceritinib in the primary leukemia cells. As shown in Fig. 7D1, ceritinib at $0.5 \mu \mathrm{M}$ significantly increased the sensitivity of the ABCB1 overexpressing primary leukemia cells to Dox, while we did not observe the same effect in the primary leukemia cells with the negative ABCB1 expression (Fig. 7D2) ( $\mathrm{p}<0.05)$. These results reveal that ceritinib enhances the efficacy of the substrate conventional chemotherapeutic drug in ABCB1-overexpressing primary leukemia cells, and it may be useful in combination regimen to combat ABCB1-mediated MDR in clinic. The schematic model illustrating the reversal of MDR by ceritinib is shown in Fig. 8.

\section{Discussion}

A chemotherapeutic drug has to reach its effective concentration around or inside of tumor cells, before it can inhibit or kill the tumor cells. The intracellular drug concentration is dependent on various parameters including absorption, distribution, metabolism, excretion, and toxicity (ADME-Tox) [34]. Among them, one of the major groups of transporters involved in ADME-Tox is the ABC superfamily, especially the ABCB1 protein. The ABCB1 is expressed at a low or very low level in normal hematopoietic cells, while having a high expression level in some MDR leukemia cells. Many clinical studies have shown that ABCB1 expression level has an inverse relationship with treatment outcome in leukemia $[11,35,36]$. With the

Fig. 7. Ceritinib increased the intracellular accumulation of Dox and enhanced the cytotoxicity of Dox in primary leukemia blasts with ABCB1-overexpression. Ten newly diagnosed patients' bone marrow samples were collected. We presented data from two representative patients out of these patients here (Patient 1 and Patient 2). The expression level of ABCB1 was positive in the patient 1 and negative in the patient 2. Mononuclear cells were isolated as described in the Materials and Methods section. (A1, A2) The expression of ABCB1 in primary leukemia blasts was determined by flow cytometry. Red and blank histograms represent the isotype control and ABCB1 expression. (B1, B2) Intracellular accumulation of Dox in primary leukemia blasts with or without ceritinib (VRP is as the positive control) treatment was determined by flow cytometry. (C1, C2) The relative levels of intracellular accumulation of Dox (expressed in mean fluorescent intensity unit) as determined in above were plotted in bar graphs. (D1, D2) Dox cytotoxicity in primary leukemia blasts treated with or without ceritinib. Cytotoxicity was determined by MTT assay as described in the Materials and Methods section. Results are represented as the mean \pm SD. ${ }^{*} \mathrm{P}<0.05$ and ${ }^{* *} \mathrm{P}<0.01$ denote the significant differences from the control group.

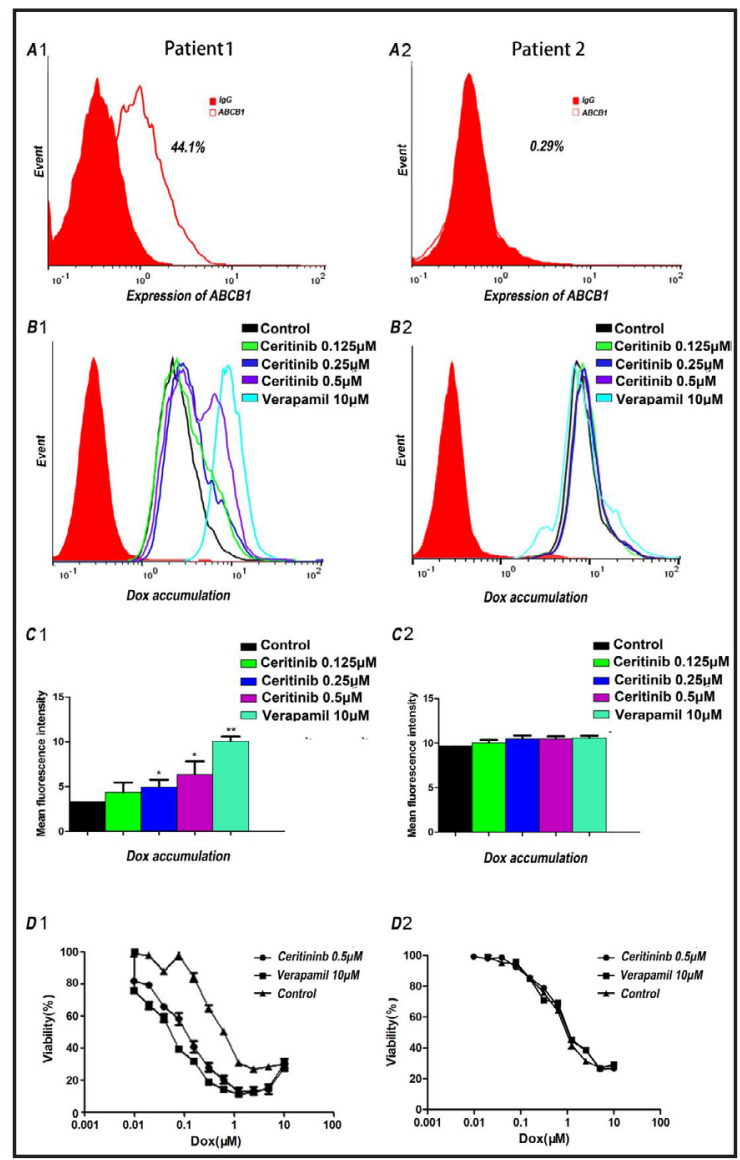


Fig. 8. A schematic model illustrating the reversal of MDR by ceritinib. Overexpressing ABCB1 in the MDR cells resulted in an efflux of anti-cancer drugs. When the MDR cancer cells were treated with ceritinib, the intracellular accumulation of conventional anti-cancer drugs was increased in the tumor cells, resulting in sensitization to anti-cancer drugs.

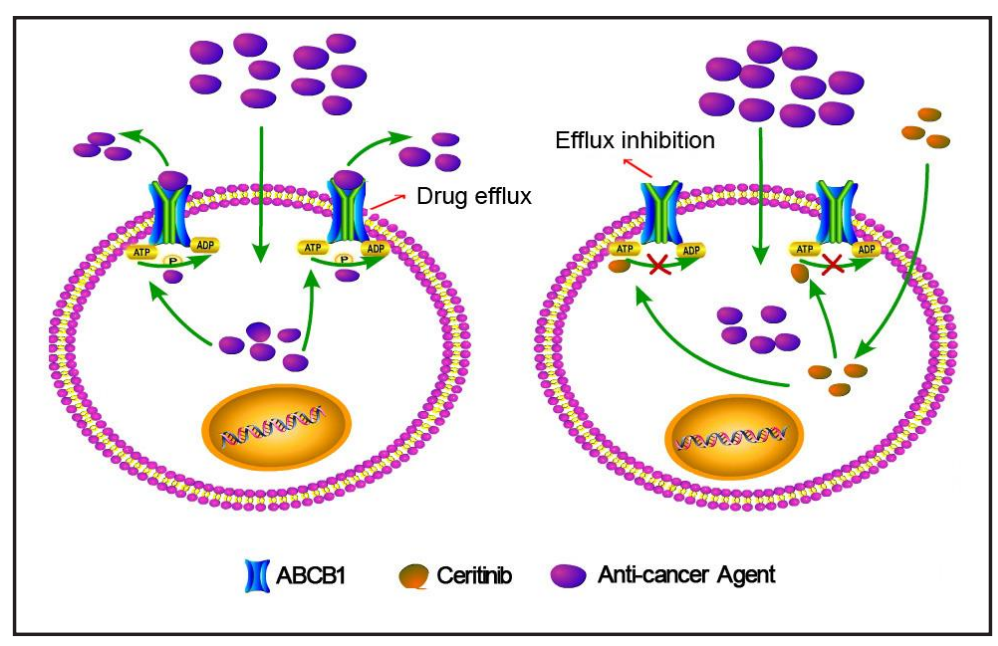

energy from ATP hydrolysis, the ABCB1 protein pumps out hydrophobic anticancer drugs, including vinca alkaloids (vinblastine and vincristine), anthracyclines (doxorubicin and daunorubicin), epipodophyllotoxins, taxanes and some TKIs, leading to MDR. Although some drugs have been reported to be highly effective and well tolerated in leukemia patients, such as imatinib, a TKI inhibitor, which is a clinic first-line drug for treating CML. Resistance to chemotherapy drugs emerges after treatment, especially in ABCB1-overexpressing cells, which highlights the need for improved therapies. Based on this status, increasing efforts have been made to overcome this issue. For instance, calcium antagonists, calmodulin inhibitors, ring spore fungus element, estrogen antagonist, protein kinase $C$ inhibitors, glutathione (GSH) inhibitors, and quinidine, have been reported to inhibit the ABCB1 to restore the MDR cancer cell sensitivity to chemotherapeutic drugs [36-38]. However, the toxicity of these drugs restricts their clinic use. More efficient and low toxicity reversal drugs still need to be sought.

Ceritinib (LDK378/Zykadia) is a clinically approved second generation TKI specifically targeting the ALK, which has been found to be more potent than the first generation ALK inhibitor crizotinib in the therapy of non-small cell lung cancer (NSCLC) [36, 37, 39]. Our previous study showed that ceritinib had potent reversing activity in ABCB1-expressing MDR solid tumor cells in vitro and in vivo, through competing with substrates to interact with the substrate-binding sites of ABCB1, thereby inhibiting the efflux activity of the ABCB1 transporter [39]. It has been reported that the expression and function of $A B C$ transporters differ in different human races, tumor types, and cell or tissue types [40]. Therefore, we hypothesized that leukemia cells and solid tumor cells were also different in terms of ABCB1-mediated drug resistance. To this end, we used the leukemia cell lines K562 and K562/adr to test whether ceritinib, like in solid tumor [39], could also enhance the efficacy of conventional chemotherapeutic drugs in human ABCB1-overexpressing MDR leukemia. In fact, our data support that ceritinib can inhibit the efflux of ABCB1-mediated the conventional chemotherapeutic drugs to enhance the accumulation of these drugs in MDR leukemia cells, and to restore the sensitivity of ABCB1-overexpressing MDR cells to these conventional chemotherapeutic drugs, while having weak effect on their parental cells. Additionally, although ceritinib has been shown excellent antiproliferation activity in different ALK-positive cancer cells by inhibiting ALK phosphorylation and subsequent downstream survival signaling of ALK, such as ERK, p-ERK, AKT and p-AKT [41], some studies also have shown that activation of ERK or PI3K/AKT pathway is attributable to the resistance to conventional chemotherapeutic drugs in various cancer cells $[42,43]$. In our study, we found that ceritinib could reverse ABCB1-mediated MDR and enhance the efficacy of conventional chemotherapeutic drugs at more than $85 \%$ cell survival concentration. These effects were not due to ALK inhibition by ceritinib, because we did not find that ceritinib blocked the phosphorylation of AKT and ERK1/2 both in K562 and K562/adr cells. It suggests that 
ceritinib-induced enhancement of the cytotoxicity of chemotherapeutic drugs in K562/adr cells is not dependent on its antagonism of the phosphorylation of AKT or ERK1/2. Besides, in our study, ceritinib had also been testified to have a reversal MDR action in nude mice model. Even more importantly, ceritinib as a reversal agent was also verified to play a role in the ABCB1-overexpressing primary leukemia cells due to increasing the accumulation of Dox in a concentration-dependent manner and enhancing the cytotoxicity of Dox. All these results provide us a possibility that combining conventional chemotherapeutic drugs with ceritinib can increase the efficacy of chemotherapy and delay disease progression in the future leukemia therapy.

\section{Conclusion}

Taken together, our study portends a possibility that the detection of ABCB1 expression in all leukemia patients, especially in refractory or relapsed leukemia patients, is needed in the future clinic practice, and according to ABCB1 expression level, a suitable dose of ceritinib that inhibits the function of ABCB1 can be chosen to sensitize MDR cells to concurrent chemotherapy drugs used in clinic.

\section{Acknowledgements}

This work was supported by grants from the National Nature Scientific Foundation (No. 81673463), Science and Technology Research Group Fund of Guangdong Province (No. 2016A030312014), Guangzhou Planned Project of Science and Technology, China (No. 201707010279) and the International Collaboration Science Research Foundation of Guangdong Province (No. 2013B051000046).

\section{Disclosure Statement}

The authors declare no Disclosure Statement.

\section{References}

$1 \mathrm{Li}$ J, Zhu H, Hu J, Mi J, Chen S, Chen Z, Wang Z: Progress in the treatment of acute promyelocytic leukemia: optimization and obstruction. Int J Hematol 2014;100:38-50.

2 Efficace F, Cannella L: The value of quality of life assessment in chronic myeloid leukemia patients receiving tyrosine kinase inhibitors. Hematology. American Society of Hematology. Education Program 2016;2016:170-179.

-3 Jaglowski SM, Byrd JC: Novel Therapies and Their Integration into Allogeneic Stem Cell Transplant for Chronic Lymphocytic Leukemia. Biol. Blood Marrow Tr 2012;18:S132-S138.

-4 Staud F, Pavek P: Breast cancer resistance protein (BCRP/ABCG2). Int J Biochem Cell Biol 2005;37:720725.

-5 Choudhuri S, Klaassen CD: Structure, function, expression, genomic organization, and single nucleotide polymorphisms of human ABCB1 (MDR1), ABCC (MRP), and ABCG2 (BCRP) efflux transporters. Int. J. Toxicol 2006;25:231-259.

6 Huang L, Fu L: Mechanisms of resistance to EGFR tyrosine kinase inhibitors. Acta pharmaceutica Sinica. B 2015;5:390-401.

7 Gillet J, Efferth T, Steinbach D, Hamels J, de Longueville F, Bertholet V, Remacle J: Microarray-based detection of multidrug resistance in human tumor cells by expression profiling of ATP-binding cassette transporter genes. Cancer Res 2004;64:8987-8993. 


\section{Cellular Physiology Cell Physiol Biochem 2018;46:2487-2499 \begin{tabular}{l|l|l} 
and Biochemistry 10.1159/000489655 2018 & $\begin{array}{l}\text { C) } 2018 \text { The Author(s). Published by S. Karger AG, Basel } \\
\text { www.karger.com/cpb }\end{array}$
\end{tabular}

8 Ferreira MU, Gyemant N, Madureira AM, Molnar J: Inhibition of P-glycoprotein transport activity in a resistant mouse lymphoma cell line by diterpenic lactones. Anticancer Res 2005;25:3259-3262.

-9 Quiney C, Billard C, Faussat A, Salanoubat C, Kolb J: Hyperforin inhibits P-gp and BCRP activities in chronic lymphocytic leukaemia cells and myeloid cells. Leukemia Amp; lymphoma 2007;48:1587-1599.

$\checkmark 10$ Anreddy N, Gupta P, Kathawala R, Patel A, Wurpel J, Chen Z: Tyrosine Kinase Inhibitors as Reversal Agents for ABC Transporter Mediated Drug Resistance. Molecules 2014;19:13848-13877.

11 Rumjanek VM, Vidal RS, Maia RC: Multidrug resistance in chronic myeloid leukaemia: how much can we learn from MDR-CML cell lines? Bioscience Rep 2013;33:875-888.

12 Eadie LN, Hughes TP, White DL: ABCB1 Overexpression Is a Key Initiator of Resistance to Tyrosine Kinase Inhibitors in CML Cell Lines. Plos One 2016;11:e161470.

-13 Radic-Sarikas B, Halasz M, Huber K, Winter GE, Tsafou KP, Papamarkou T, Brunak S, Kolch W, SupertiFurga G: Lapatinib potentiates cytotoxicity of YM155 in neuroblastoma via inhibition of the ABCB1 efflux transporter. Sci Rep 2017;7:3091.

14 Tao LY, Liang YJ, Wang F, Chen LM, Yan YY, Dai CL, Fu LW: Cediranib (recentin, AZD2171) reverses ABCB1and ABCC1-mediated multidrug resistance by inhibition of their transport function. Cancer Chemother Pharmacol 2009;64:961-969.

15 Yang K, Chen Y, To KK, Wang F, Li D, Chen L, Fu L: Alectinib (CH5424802) antagonizes ABCB1- and ABCG2mediated multidrug resistance in vitro, in vivo and ex vivo. Exp Mol Med 2017;49:e303.

16 Yang CH, Huang CJ, Yang CS, Chu YC, Cheng AL, Whang-Peng J, Yang PC: Gefitinib reverses chemotherapy resistance in gefitinib-insensitive multidrug resistant cancer cells expressing ATP-binding cassette family protein. Cancer Res 2005;65:6943-6949.

17 Shi Z, Peng XX, Kim IW, Shukla S, Si QS, Robey RW, Bates SE, Shen T, Ashby CJ, Fu LW, Ambudkar SV, Chen ZS: Erlotinib (Tarceva, OSI-774) antagonizes ATP-binding cassette subfamily B member 1 and ATP-binding cassette subfamily G member 2-mediated drug resistance. Cancer Res 2007;67:11012-11020.

18 Kuang YH, Shen T, Chen X, Sodani K, Hopper-Borge E, Tiwari AK, Lee JW, Fu LW, Chen ZS: Lapatinib and erlotinib are potent reversal agents for MRP7 (ABCC10)-mediated multidrug resistance. Biochem Pharmacol 2010;79:154-161.

19 Tong XZ, Wang F, Liang S, Zhang X, He JH, Chen XG, Liang YJ, Mi YJ, To KK, Fu LW: Apatinib (YN968D1) enhances the efficacy of conventional chemotherapeutical drugs in side population cells and ABCB1overexpressing leukemia cells. Biochem Pharmacol 2012;83:586-597.

20 Zhou WJ, Zhang X, Cheng C, Wang F, Wang XK, Liang YJ, To KK, Zhou W, Huang HB, Fu LW: Crizotinib (PF02341066) reverses multidrug resistance in cancer cells by inhibiting the function of P-glycoprotein. $\mathrm{Br} \mathrm{J}$ Pharmacol 2012;166:1669-1683.

-21 Tiwari AK, Sodani K, Wang SR, Kuang YH, Ashby CJ, Chen X, Chen ZS: Nilotinib (AMN107, Tasigna) reverses multidrug resistance by inhibiting the activity of the ABCB1/Pgp and ABCG2/BCRP/MXR transporters. Biochem Pharmacol 2009;78:153-161.

22 Marsilje TH, Pei W, Chen B, Lu W, Uno T, Jin Y, Jiang T, Kim S, Li N, Warmuth M, Sarkisova Y, Sun F, Steffy A, Pferdekamper AC, Li AG, Joseph SB, Kim Y, Liu B, Tuntland T, Cui X, Gray NS, Steensma R, Wan Y, Jiang J, Chopiuk G, Li J, Gordon WP, Richmond W, Johnson K, Chang J, Groessl T, He Y, Phimister A, Aycinena A, Lee CC, Bursulaya B, Karanewsky DS, Seidel HM, Harris JL, Michellys P: Synthesis, structure-activity relationships, and in vivo efficacy of the novel potent and selective anaplastic lymphoma kinase (ALK) inhibitor 5-chloro-N2-(2-isopropoxy-5-methyl-4-(piperidin-4-yl)phenyl)-N4-(2-(isopropylsulf onyl) phenyl)pyrimidine-2, 4-diamine (LDK378) currently in phase 1 and phase 2 clinical trials. J Med Chem 2013;56:5675-5690.

23 Nishio M, Murakami H, Horiike A, Takahashi T, Hirai F, Suenaga N, Tajima T, Tokushige K, Ishii M, Boral A, Robson M, Seto T: Phase I Study of Ceritinib (LDK378) in Japanese Patients with Advanced, Anaplastic Lymphoma Kinase-Rearranged Non-Small-Cell Lung Cancer or Other Tumors. J Thorac Oncol 2015;10:1058-1066.

24 Pera B, Calvo-Vidal MN, Ambati S, Jordi M, Kahn A, Diaz JF, Fang W, Altmann KH, Cerchietti L, Moore MA: High affinity and covalent-binding microtubule stabilizing agents show activity in chemotherapy-resistant acute myeloid leukemia cells. Cancer Lett 2015;368:97-104.

-25 Oh S, Song J, Gil J, Kim J, Yeom Y, Moon E: ERK activation by thymosin-beta-4 (TB4) overexpression induces paclitaxel-resistance. Exp Cell Res 2006;312:1651-1657.

26 Gagnon V, Van Themsche C, Turner S, Leblanc V, Asselin E: Akt and XIAP regulate the sensitivity of human 


\section{Cellular Physiology Cell Physiol Biochem 2018;46:2487-2499

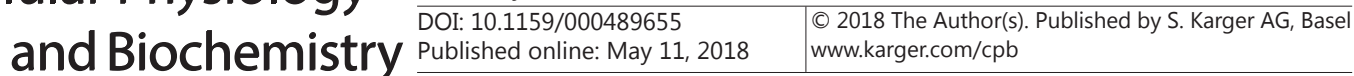

uterine cancer cells to cisplatin, doxorubicin and taxol. Apoptosis 2008;13:259-271.

27 Brozik A, Hegedus C, Erdei Z, Hegedus T, Ozvegy-Laczka C, Szakacs G, Sarkadi B: Tyrosine kinase inhibitors as modulators of ATP binding cassette multidrug transporters: substrates, chemosensitizers or inducers of acquired multidrug resistance? Expert Opin Drug Met 2011;7:623-642.

28 Coculova M, Imrichova D, Seres M, Messingerova L, Bohacova V, Sulova Z, Breier A: The expression of P-glycoprotein in leukemia cells is associated with the upregulated expression of nestin, a class 6 filament protein. Leukemia Res 2016;48:32-39.

29 Fu L, Liang Y, Deng L, Ding Y, Chen L, Ye Y, Yang X, Pan Q: Characterization of tetrandrine, a potent inhibitor of P-glycoprotein-mediated multidrug resistance. Cancer Chemoth Pharm 2004;53:349-356.

30 Dai CL, Tiwari AK, Wu CP, Su XD, Wang SR, Liu DG, Ashby CR, Huang Y, Robey RW, Liang YJ, Chen LM, Shi CJ, Ambudkar SV, Chen ZS, Fu LW: Lapatinib (Tykerb, GW572016) Reverses Multidrug Resistance in Cancer Cells by Inhibiting the Activity of ATP-Binding Cassette Subfamily B Member 1 and G Member 2. Cancer Res 2008;68:7905-7914.

31 Mahon FX, Belloc F, Lagarde V, Chollet C, Moreau-Gaudry F, Reiffers J, Goldman JM, Melo JV: MDR1 gene overexpression confers resistance to imatinib mesylate in leukemia cell line models. Blood 2003;101:23682373.

32 Szaloki G, Krasznai ZT, Toth A, Vizkeleti L, Szollosi AG, Trencsenyi G, Lajtos I, Juhasz I, Krasznai Z, Marian T, Balazs M, Szabo G, Goda K: The strong in vivo anti-tumor effect of the UIC2 monoclonal antibody is the combined result of Pgp inhibition and antibody dependent cell-mediated cytotoxicity. Plos One 2014;9:e107875.

-33 Cheson BD, Bennett JM, Kopecky KJ, Buchner T, Willman CL, Estey EH, Schiffer CA, Doehner H, Tallman MS, Lister TA, Lo-Coco F, Willemze R, Biondi A, Hiddemann W, Larson RA, Lowenberg B, Sanz MA, Head DR, Ohno R, Bloomfield CD: Revised recommendations of the International Working Group for Diagnosis, Standardization of Response Criteria, Treatment Outcomes, and Reporting Standards for Therapeutic Trials in Acute Myeloid Leukemia. J Clin Oncol 2003;21:4642-4649.

34 Boesch D, Loor F: Extent and persistence of P-glycoprotein inhibition in multidrug-resistant P388 cells after exposure to resistance-modifying agents. Anti-Cancer Drug 1994;5:229-238.

-35 Naito M, Tsuge H, Kuroko C, Koyama T, Tomida A, Tatsuta T, Heike Y, Tsuruo T: Enhancement of cellular accumulation of cyclosporine by anti-P-glycoprotein monoclonal antibody MRK-16 and synergistic modulation of multidrug resistance. Journal of the National Cancer Institute 1993;85:311-316.

-36 Shaw AT, Kim D, Mehra R, Tan DSW, Felip E, Chow LQM, Camidge DR, Vansteenkiste J, Sharma S, De Pas T, Riely GJ, Solomon BJ, Wolf J, Thomas M, Schuler M, Liu G, Santoro A, Lau YY, Goldwasser M, Boral AL, Engelman JA: Ceritinib in ALK-Rearranged Non-Small-Cell Lung Cancer. New Engl J. Med 2014;370:11891197.

37 Richly H, Kim TM, Schuler M, Kim DW, Harrison SJ, Shaw AT, Boral AL, Yovine A, Solomon B: Ceritinib in patients with advanced anaplastic lymphoma kinase-rearranged anaplastic large-cell lymphoma. Blood 2015;126:1257-1258.

-38 Mello JCD, Moraes VW, Watashi CM, da Silva DC, Cavalcanti LP, Franco MK, Yokaichiya F, de Araujo DR, Rodrigues T: Enhancement of chlorpromazine antitumor activity by Pluronics F127/L81 nanostructured system against human multidrug resistant leukemia. Pharmacol Res 2016;111:102-112.

39 Hu J, Zhang X, Wang F, Wang X, Yang K, Xu M, To KKW, Li Q, Fu L: Effect of ceritinib (LDK378) on enhancement of chemotherapeutic agents in ABCB1 and ABCG2 overexpressing cells in vitro and in vivo. Oncotarget 2015;6:44643.

40 Imai Y, Nakane M, Kage K, Tsukahara S, Ishikawa E, Tsuruo T, Miki Y, Sugimoto Y: C421A polymorphism in the human breast cancer resistance protein gene is associated with low expression of Q141K protein and low-level drug resistance. Mol. Cancer Ther 2002;1:611-616.

41 Pan P, Yu H, Liu Q, Kong X, Chen H, Chen J, Liu Q, Li D, Kang Y, Sun H, Zhou W, Tian S, Cui S, Zhu F, Li Y, Huang Y, Hou T: Combating Drug-Resistant Mutants of Anaplastic Lymphoma Kinase with Potent and Selective Type-I(1/2) Inhibitors by Stabilizing Unique DFG-Shifted Loop Conformation. ACS Cent Sci 2017;3:12081220.

42 West KA, Castillo SS, Dennis PA: Activation of the PI3K/Akt pathway and chemotherapeutic resistance. Drug Resist Updat 2002;5:234-248.

43 Navolanic PM, Steelman LS, McCubrey JA: EGFR family signaling and its association with breast cancer development and resistance to chemotherapy (Review). Int J Oncol 2003;22:237-252. 